\title{
Social Web Applications as Means to Enhance Lifelong Learning and Professional Development of Teachers: A Tool to Support Assessment of Their Impact
}

\author{
Andreas Koskeris, MA \\ Computer Technology Institute and Press "Diophantus", Greece, \\ Computer Engineering and Informatics Department, \\ University of Patras, Greece \\ Georgia Boura, BSC \\ Computer Engineering and Informatics Department, \\ University of Patras, Greece \\ Prof. John Garofalakis, \\ Computer Technology Institute and Press "Diophantus", Greece, \\ Computer Engineering and Informatics Department, \\ University of Patras, Greece
}

URL:http://dx.doi.org/10.19044/esj.2020.v16n19p96

\begin{abstract}
The application of new technologies in classroom has made the need for constant professional development more important for teachers. They should be able to keep up with the technological development in the classroom. Their professional development includes constant upgrade of their skills and knowledge on how they can meet the needs of their students or address issues derived from ICTs application in classroom. Social Web applications are providing new opportunities to build and gain such professional development by assisting to remain current on skills and issues important for a professional role. Aim of the present work is to contribute to the assessment of impact of Social Web applications for teachers' professional development by presenting specific case studies and proposing an ICT tool to be used for the collection of useful quantitative indicators supporting this impact assessment. The assesment derived from a specific showcase of its application, provided real case results on the usage of Social Web tools from teachers which could be a useful asset towards the design of teacher training programs for the effective use of social networking tools.
\end{abstract}

Keywords: Social networking, evaluation, informatics, education 


\section{Introduction}

In an increasingly uncertain world, professionals must build upon their employability by learning new skills, having new experiences, being clear about what their wants and where they are going, and by communicating with others to broaden and strengthen their professional development and business horizons. This is even more important as a result of constant technological change. Ongoing professional development is one way that could alleviate the barriers to the implementation of Information and Communication Technologies (ICT) (Shamoail, 2005). To deal with this need, professional development must be considered as derived from a constant training procedure (Anastasiou, Giavrimis, Papastamatis, Valkanos, 2011) and as a continuous learning cycle (Edsurge, 2014).

In this document we focus in a specific category of professionals, the Teaching profession in primary and secondary education. The application of new technologies in classroom has made the need for constant professional development even more important for them. Teachers should be able to keep up with the technological development in the classroom and beyond (Kouzov, Pavlova, 2016). Integrating ICT into teaching is a complex process and one may encounter a number of difficulties (Bhagwan \& Sharma, 2015). Teacher professional development is a development that they seek on their own so that they can meet the needs of their students or address issues derived from ICTs application in classroom (Smith, 2011) leading to a recognition as "reformminded" educator (Luehmann \& Tinelli, 2008).

Social networking /Social Web is the technology to support connecting people with various ways (Groff, et.al, 2009). The advent of Social Web allowed users to enhance their actions when accessing the internet not only for searching information but above all to interact, collaborate, and share contents (Pereira \& Santana, 2013). The Social Web advent has changed relationship to information and lead to personal and professional development opportunities outside of formal education (Babatunde, 2017). Aim of the present work is to contribute to the assessment of impact of Social Web applications for teachers' professional development.

The research was carried out as basis for a further second step work (as given in the relevant section). Based on this prerequisite, it was chosen as the most appropriate to use the survey research method (Cohen et al., 2008, p 290) concerning the collection of data at a particular time with a view to a possible export of generalized conclusions. For the implementation of the research the technique of desk research has been used combined with a field reserach to collect data from a specialised e-tool. 


\section{Teachers' Professonal Development and Social Web}

Professional development activities for teachers include: individual development, continuing education, and in-service education or staff development, curriculum writing, peer collaboration, study groups, peer coaching or mentoring, classroom visitation, attendance of conferences, action research, publication of papers, etc. Professional development programs are important to respect and encourage the leadership development of teachers (Tuviera-Lecaroz, 2002).

One current trend (Tuviera-Lecaroz, 2002) on professional development activities for teachers is networking. Teachers join on-line study groups within and outside the school to explore new and better ways of teaching and to share lesson plans, web-based resources, and experiences with web-based activities. Social networking (Social Web) tools are a current trend to support this process. Networking is defined (networking.pdf) as establishing and maintaining informal relationships with people whose acquaintance or friendship could bring advantages such as job or business opportunities. In professional networking, people are willing to learn about other professionals and their career experiences.

Social networking tools are characterized by the following issues which differentiate them from other World Wide Web (www) applications (Cachia, 2008):

- Providing a way to present oneself

- Externalization of own data

- Provision of new ways for community formation

- Enhance bottom up activities

- Ease of use

- Reorganization of the Internet "geography" by supporting new ways to access the www

They are also having strong application on education by serving as a potential vehicle to deliver a richer and more enhanced learning experience for students (Dunn, 2013) by supporting blended learning.

In relation to professional development for teachers, there are several examples on how Social Web is providing new opportunities to build and gain to professional development by assisting to remain current on skills and issues important for a professional role:

- Using twitter as means of communication reform between teachers (Kent County Council, 2011). Twitter can be a great way to connect and have questions answered not only to help a teacher but also other school staff and students (Bruguera et.al., 2019; Couros \& Hilt, 2011). 
- Using professional social networks to research people and companies and reconnect with past colleagues (e.g. linkedin)

- Wikis (Anzai, 2010) which can provide an important workplace to construct shared knowledge within an educational community.

- Creation of groups/online communities and tools such as blogs and forums to initiate discussions with a new way comparing with emails (Stewart, 2009; Instone, 2005; Luehmann, 2008). Such groups facilitate a new community based approach to mentoring which increases access to constant learning and support opportunities.

- Specialized Peer learning tools to enhance continuous learning experiences and teacher retention.

- Shared e-portfolios allowing reflection with colleagues (Beach, 2012). Novice teachers receiving feedback from veteran mentors could benefit from more experienced perspective on their work.

Of course, using the tools is not an efficient professional development tool on its own, several important considerations have to be taken seriously So as to avoid problems and drawbacks (Stone, 2010; Dikova \& Tepavicharova, 2019):

- Knowing the goals from the beginning

- Write well and organize (e.g. a forum) to avoid chaos

- Proper use of visualization and multimedia content

- Don't post information to often

- Avoid the risk of online activities to become a threat for productivity

- Linking with other communities

- Encourage people to interact

- Evaluate / reflect on results

- Monitoring, respect privacy and copyright

Based on the bibliography, the potential problems which can lead to drawbacks/barriers on social networking effective applications in the area of professional development of teachers can be categorized as follows:

- Lack of time and technical support (Demkanin et.al., 2008; Green \& Powers, 2016)

- Stress related with technology, lack of confidence and technophobias, fear of "staying back" (Karalis \& Koskeris, 2016; Mlotshwa, 2013; Shamoail, 2005; Huang, 2017) and impact on self-esteem (Muqaddas et.all., 2017).

- Negative attitudes and presumptions towards new technologies (Karalis \& Koskeris, 2016; Bhagwan, Sharma, 2015) 
- Fear on what others can say in case of non-proper use of some tools (Karalis \& Koskeris, 2016; Jones, 2004)

- Safety considerations (Carter et.al., 2013)

Solution towards dealing with most of the above issues can come through effective training (including self-training) (Jones, 2004; Shamoail, 2005), based on properly identified educational needs (Kent County Council, 2011).

To utilize social media, a teacher has to know how to do this with effectiveness and safety. At the same time, on skills level, he/she must be able to act on three levels (Project tomorrow, 2011):

- Enabling himself/herself or others to reach the tools potential.

- Engaging creativity and critical thinking.

- Empowering the creation of new knowledge.

A proper educational program for teachers in order to make them "social media" ready, has to provide the above needed knowledge and skills. It's basic aims have to be (Cachia et.al, 2009) (Tuviera-Lecaroz, 2002):

- Assist teachers to uncover the professional beliefs about social media and their utilization.

- Encourage them to discover their experiences and assumptions.

- Allow time for reflection and deeper understanding.

- Encourage to go beyond "fitting into the curriculum".

- Help to identify difficulties and how to deal with them.

- Allow creativity through groups work coordinated by a facilitator.

- Utilize case studies.

An important element towards successful design of such educational programs for teachers is their proper evaluation leading to hints and suggestions for their constant improvement and evolution.

Social Networking tools are providing impact on three levels (Cachia, 2008):

- Impact on way people manage their identities

- On patterns of behaviors

- On thinking and disclosure of privacy

A successful education program has to be evaluated towards the provision of needed knowledge and skills to achieve such results (Beach, 2012) as long as on the effective use of the tools (Edsurge, 2014).

The use of metrics for specific indicators on social networking application from teachers after an education program completion can provide importance evidence to support such evaluation (Barrett et.al., 2011). 
Examples of such data collection are: the levels of usage of a wiki environment (Brunvand et.al., 2012), frequency on accessing a blog (Luehmann, 2008), number of comments and reflections over a post (Madeira \& Slota, 2009), number of words in a post or a comment (Luehmann \& Tinelli, 2008), members and level of activation in a group (Hatter, 2012), number of facilitated discourses (Coutinho \& Lisboa, 2013). In the next section we are presenting some specific case studies on Social Networking applications for teachers' professional development enhancement. This initial desk research is providing the basis for the needed next steps of specific field research to follow. For the presented work, these next steps have been done using an ICT tool which was developed specificaly for this purpose.

\section{Case Studies}

\section{A professional Development project for developing the use of ICT in Science Education in Finland (Demkananin, et.al., 2008) \\ Description}

This project deals with the need to enhance teachers' skills in order to be able to effectively use new ICT in the science teaching. Integration of Social Interaction into teaching methods as long as between teachers has been identified as one of the aims of such work.

To achieve this, a specialized training program have been designed and applied including activities allowing interaction and exchange of experiences between participating teachers (during the program as long as in its follow up actions.

\section{Lessons Learnt}

The teachers applied what they learnt in real cases with their students and their feedback was positive on the whole approach and its results. The evaluation of the activity focused mainly on how teachers feel about this transfer of what they learnt in practice in their schools and not on the importance of their interaction with other teachers.

\section{Recommendations}

Teacher beliefs and preconceptions about ICT usage have been identified as a potential drawback to deal within. The teacher must be $100 \%$ confident in order to be able to act as facilitator for his/her students in the field of ICT effective use in Science teaching. 


\section{Utilization of Facebook for teachers' professional development (Al-Jarf,} 2013)

\section{Description}

This study concerns teachers of English as a Second Language and how they can utilize facebook for the professional development. The study included cases from teachers from different countries and cultures.

\section{Lessons Learnt}

Facebook can provide effective opportunities for the creation of online learning communities for peer-to-peer interaction between teachers.

\section{Recommendations}

Topics to focus when using facebook groups:

- How to become a teacher

- Teaching via skype

- Grammar usage rules

- Improving students' accents

- Ideas for increasing comprehension

- Communicative activities

- How to reinforce speaking

- Problems in teaching writing, reading, grammar, pronunciation.

\section{PROEDI social network (Coutinho \& Lisboa, 2013)}

\section{Description}

In order to investigate the potential of educational networking as a source for teachers' growth, a social network named PROEDI was created in the beginning of 2011. In this project, the Interconnected model of teacher professional growth (Clarke and Hollingsworth, 2002) was the basic framework for the analysis of professional growth in informal settings. In this study, the conceptual framework of the research was presented, and some evidence obtained on the analysis of discussion forums created inside the community underpin a discussion on the challenges and opportunities that social networking offer for teacher education.

\section{Lessons Learnt}

Main findings:

- Need to establish concrete goals and, more importantly, demonstrate effort in achieving them.

- There must be a perfect harmony between the technical and human factors in order to guarantee the flow of information and, finally, the production of knowledge. 
- Beam interaction has a significant increase in the information exchange and knowledge construction.

- It was revealed that the e-moderator makes a difference in virtual environments, not only providing knowledge management, but also helping members to develop autonomy and begin to be coresponsible for their own learning and the environment management.

- Besides the important role of the e-moderator, learning in an environment with a predominantly asynchronous communication will only have good results when there is perfect harmony between human and technical factors of communication.

\section{Recommendations}

- Utilization of social tools must accompany the teachers during their entire career, because knowledge is renewed every day, and there is a need to change our practices and attitudes towards the new.

- Adaptation of a philosophy very much in vogue in the social context we live.

\section{Specific case study for k12 teachers (Smith, 2011) Description}

The purpose of this study was to examine if the social network Classroom 2.0 could be used as a source of effective professional development for K12 teachers.

A non-experimental study was conducted to examine the relationship between how teachers' reported using the social network Classroom 2.0 for personal professional development and the criteria for effective professional development, teachers' integration practices, and teachers' ability to collaborate and communicate with colleagues. A self-administered questionnaire was used to gather data.

\section{Lessons Learnt}

The results suggested that there was a statistically significant relationship between the criteria for effective professional development and how K-12 teachers report using social media networks.

There was also evidence to support a relationship between the frequency of technology integration and the use of Classroom 2.0 to seek information that would enhance professional practice. The results also suggested that there was a statistically significant relationship between:

- technology integration practices and how K-12 teachers reported using social media networks. 
- the frequency of collaboration with colleagues and how K-12 teachers reported using social media networks

- the ability to communicate professionally about technology integration with colleagues and how K-12 teachers report using social networking.

\section{Recommendations}

Based on the findings of this study, several recommendations can be made for future research on using social media community in education as a form of personal professional development:

- Further research should be conducted on using social media networks to improve teachers' professional communication and collaboration with their peers.

- More research should be done concerning the correlation between technology and its use with social media community in education for professional development.

- Research should be conducted to determine what impacts teachers use of social media community in education (i.e. user friendly, easy access, etc).

Finally it is important to mention that the findings show that many teachers were not taking advantage of the collaborative nature of social media networks. Majority of the teachers reported that they had never used the tool while others reported mild use.

\section{Using twitter and blogs to draw experience from around the world}

\section{(Barrett et.al., 2011)}

\section{Description}

Description of the experience of a specific teacher on using twitter and blogs to be in touch with other prior to using social media in the classroom. This has the effect of confirming presuppositions and prejudices, and means that, when complex situations arise, beyond own experience and those around you, the support available from colleagues may be narrow or limited.

\section{Lessons Learnt}

One school of thought believes that the impact social media had on professional learning is that we are so easily able to draw on ideas from around the world.

\section{Recommendation}

In the connected world of social media, although you may still have a limited number of people you connect with, they are spread around the world 
and in very different contexts to yours. These senior leaders have to be ready to share their perspectives and challenge their own thinking.

\section{Blogging and twitting to reflect on your own practice (Barrett et.al., 2011) \\ Description}

This case study refers to a specific teacher who left the Year 4 class teacher role, in which he spent the first two years of his teaching career, to become a lecturer in education at Plymouth University. He has been using social media throughout the course of his teacher training and career. As a teenager, Oliver used a blogging platform that his friend had created to stay in touch with friends. Consequently, when trained to be a teacher, he was comfortable returning to this social media tool to write up his teaching experiences.

\section{Lessons Learnt}

Reflecting on his placements proved a valuable process in itself. It was an activity designed solely to help shape his own thinking and to share ideas and resources with colleagues on his course.

Throughout his teaching, Oliver has considered his blog, and the process of reflection needed to write regularly on it, to be a vital aspect of his professional development. Blogging during teacher training clearly demonstrates the concept of the 'reflective practitioner', and has the ability to make concrete what is otherwise seen as an abstract, hard-to-demonstrate phrase. Oliver explains that blogging for an audience helps him to shape his thinking by 'pulling in different ideas and seeing the relevance of them, synthesizing them.'

\section{Recommendations}

The use of social media by education professionals for professional networks continues to challenge and blur the work/life boundaries. Head teachers need to accept social media as a professional tool, but also to recognize the power of self-organised learning that educators are engaging when using it. In addition to validating its use within school, time and space should be invested to allow staff members to continue self-initiated professional learning.

\section{Teachers using ICT for Professional Growth (Tuviera-Lecaroz, 2002) Description}

This paper presents a comprehensive study on what constitutes a good case of using ICTs for teachers' professional growth. 


\section{Lessons Learnt}

Technology has the potential to transform the professional environment for educators. Through the application of network technologies to research and collaborative planning, teachers can break loose from the isolating environments that the teaching profession had imposed on them in the past. Technology impacts not only on the teaching and learning process but also on the ways and opportunities educators learn.

\section{Recommendations}

A list of suggestions in relation with networking, are as follows:

- Teachers join on-line study groups within and outside the school to explore new and better ways of teaching and to share lesson plans, web-based resources, and experiences with web-based activities.

- Appointing a facilitator for on-line discussions is a big help to firsttime participants.

- For technology to be used in powerful and transformative ways, however, a certain set of conditions must prevail. Professional development is a systemic issue and its effectiveness may require structural changes or reforms.

\section{Combined conclusions on Case Studies}

We categorise the main conclusions derived from the case studies review, as follows:

1. Problems faced by teachers in their effort to utilize social networking tools for their professional development

○ Beliefs and preconceptions about ICT usage have been identified as a potential drawback to deal within

- In almost all cases teachers recognize the need for a leader/facilitator/moderator in social groups/networking tools

- Teacher' perceptions of their integration abilities will determine whether or not they use social media networks to communicate professionally with colleagues

○ The use of social media by education professionals for professional networks continues to challenge and blur the work/life boundaries. Head teachers need not only to accept social media as a professional tool, but also to recognize the power of self-organised learning that educators are engaging when using it.

- For technology to be used in powerful and transformative ways, however, a certain set of conditions must prevail. Professional development is a systemic issue and its effectiveness may require structural changes or reforms. 
2. Suggestions for the efficient design of relevant educational programs for teachers

- Teachers demand to see real cases where social networking can be useful for them for their professional development and for daily teaching activities

- Among the most important topics to focus when using social groups are:

- How to become a teacher

- Teaching via teleconference

- When designing an educational activity for teachers on how to utilize social networking for their professional development it is important to take under consideration:

- The need for reflection and sharing/collaboration with colleagues

- Engage in critical thinking (reflection on activities)

- Existence of a clearly defined objective

- Harmony between technical and human factors

- Specificity and cohesion with teachers' personal and professional goals

- Motivation for willingness to commit to learning (example motive: escaping isolation)

- Take online safety under consideration

○ Peer-to-peer interaction is one of the most recognized benefits of social networking tools for teachers and this has to be taken under consideration as an important educational need

o Teachers need to be in charge of selecting the topic of their professional development

- Increased sense of ownership for the material share within a social networking tool would result in greater frequency of collaboration

- Teachers join on-line study groups within and outside the school to explore new and better ways of teaching and to share lesson plans, web-based resources, and experiences with webbased activities.

3. Concerning suggestions for further research, these should be conducted on

○ using social media networks to improve teachers' professional communication and collaboration with their peers

o impacts of teachers' usage of social media community in education (i.e. user friendly, easy access). 


\section{Evaluation Indicators}

To evaluate the success of utilization of social networking tools for the professional development of teachers, there is an additional need (apart from collecting views as presented in the previous Section). We need to extract information also from actul usage of specific tools. The bibliography suggests several approaches and metrics focusing either on tool usage or on impact for professional development (Edsurge, 2014):

A. Post evaluate the students usage of ICT coordinated by the teacher (Shamoail, 2005),

B. Changes in confidence and on the perspective on the importance of social networks (Brunvand et.al., 2012),

C. Self-evaluation of skills per tools usage and for applications in the classroom before and after a seminar (Brunvand et.al., 2012),

D. Quantitative metrics (e.g. frequency of use, number of posts) and qualitative data collection after some period (Luehmann, 2008).

E. Usage statistics (Madeira \& Slota, 2009),

F. Evaluation of help from a tool, increase of the size of the net, sending and accepting invitations (Hatter, 2012),

G. Time spent, areas of interest, usage of resources, participation rate, correlation with grades etc (Bultmann, et.al., 2012)

H. Changes in phobias and preconceptions (Karalis \& Koskeris, 2016)

I. Specific interactions metrics between 2 persons or within a group (Kim $\&$ Lee, 2012)

Based on the above, we suggest the following types of metrics/ indicators:

- Comparing views before and within a period after a seminar (including also implicit factors such as phobias, preconceptions etc) - covering $\mathrm{B}, \mathrm{C}$ and $\mathrm{H}$ from above-

- Quantitative metrics from tools usage for professional development after a seminar - D, E, F, G, I -Action analytics (e.g. creating a group)

- Discourse analytics (e.g. initiating discussions)

- Content analytics (e.g number of blog posts)

- Context analytics (e.g. group participation on a specific issue raised)

- Indirect indicators (students usage of ICTs in classroom - A)

In the next Section we present an ICT tool which gathers information from relevant Portals and assists the researcher on the extraction of useful quantitative metrics. 


\section{A System for Collection and Processing of Evaluation Data Objectives}

In order to evaluate the efficient use of SOCIAL WEB applications by teachers, the researcher needs to have access to qualitative (eg desk research as presented in the respective Section previously, self-assessment and pre-use self-assessment questionnaires) as well as quantitative data (data from various metrics).

The objective of our work was to build an application that can help the researcher in collecting quantitative data. The developed application gets information (in a parameterized way) from collaborative educational Portals and extracts a series of specific metrics for the use of social networking tools for the professional development of teachers and the support of the educational process. It is noted that within the specific capabilities and scope of this work, a series of first metrics for extracting results from the system were selected as an initial implementation. In future expansion, depending on the needs of researchers potentially able to use the application, it is possible to add new ones.

The implemented reports for the selected metrics are evaluated and observed whether a system is used efficiently and it has an impact on the educational staff to which it is addressed. This is very important, as it gives the developers of such collaborative Portals for teachers, the opportunity to improve content, functions and judge whether it is useful to the target audience or not. Also, through such applications, it is possible to compare Portals of the same object to each other, and thus, a scale is created from the most to the less popular system.

In the presented information system the administrator imports the database records from each training Portal (with a specialized User Interface). The second system role involves user / researcher, which collect information and judge from the results of the use, which Portal users are most active in blog posts, forum posts, posts that have the highest scores, etc.

\section{Description}

The constructed system consists of two different interfaces, which are essentially two different environments, but they are interrelated: The first is the interface of the administrator and the other the interface available for the collection of data.

1. Administrator interface: The administrator can insert a properly modified, .csv file (a specific .csv prototype has been designed) which contains the database records of a collaborative learning portal. He/she selects the .csv file and click on 'Submit' in order for the data to be automatically stored in our system database. 
2. User / Researcher interface: Initially, the user must register his / her username, username and password in the login form so that it can be entered in the metrics export form. If the data is correct, it is moved to the point where hs/she views all Portal included in the system. He can select Portal and using specific forms he/she can collect quantitative data on numeric statistics, comparative information between users etc.

\section{The Administrator Interface}

\section{Uploading Portals' data}

With this functionality the administrator can import a properly modified .csv file, which contains a Portal database records he/she is interested in giving to the researchers for analysis and evaluation. Pressing the 'Browse' button opens a window to choose a file. After making sure the file is selected, pressing the Upload button uploads the file and automatically assigns all the data it contains to the application database. If no file is selected then we will see the message 'No file selected' where its name appears.

When the file is uploaded successfully and the data is recorded in the database, a message confirming it is displayed for a few seconds or minutes (depending on the file size).

\section{The user / researcher interface}

When the file is uploaded successfully and the data is recorded in the database, a message confirming it is displayed for a few seconds or minutes (depending on the file size).

In a first step the researcher selects the Portal data he/she wants to process. The system presents a list with all the integrated Portals, for selection (Figure 1).

Select a system:

Figure 1. Portal selection 
In the current version of the presented tool, the following functionalities for extracting information are given:

1. Data about member's activation within a Portal

The researcher selects a specific user of a Portal to locate statistical information (and not private one) relevant with his/her activation. (e.g. total blog posts within a period, total educational scenarios uploaded).

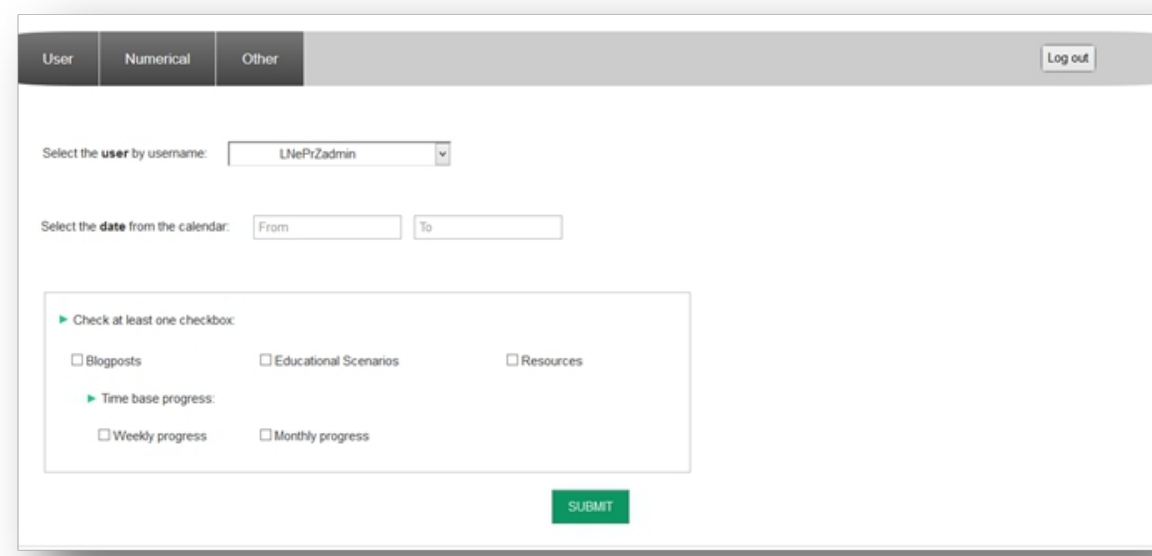

Figure 2. Results forms (1)

2. Users belonging in communities

The researcher selects a specific period to locate users that belong in communities. The system can collate this information with activation on blog posts, resources uploaded etc.

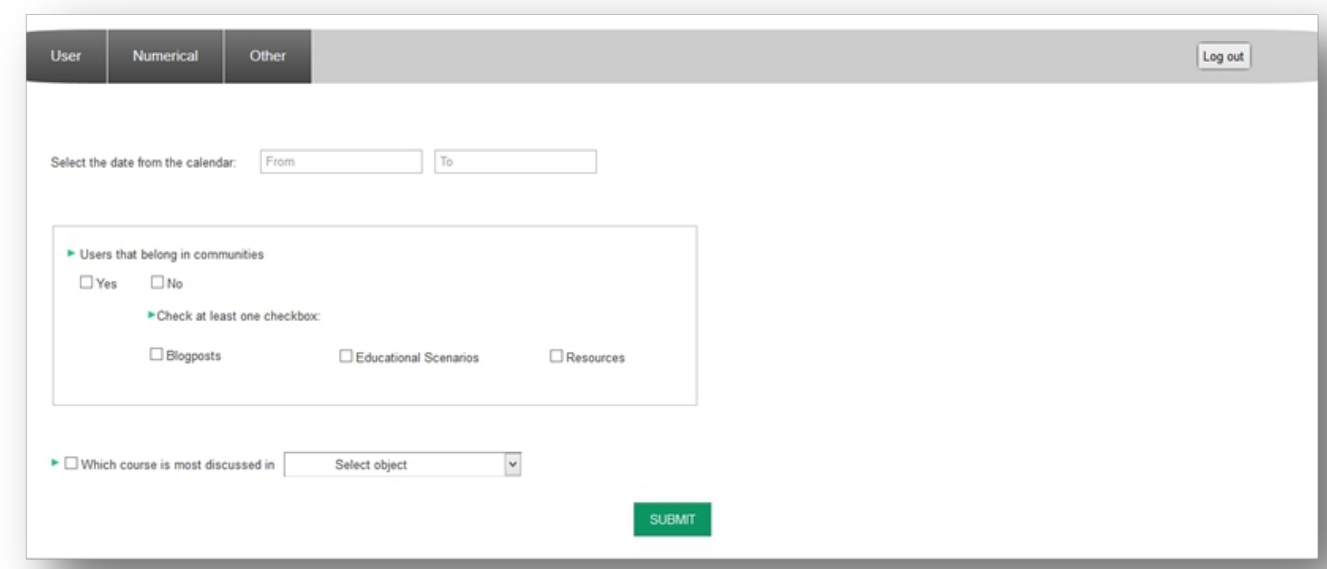

Figure 3. Results forms (2) 
3. Users with higher rating and/or more activation

With this feature, the researcher can locate the teachers with the higher levels on rating for their posts and / or the ones with more activation in the Portal. Results can be presented also comparatively.

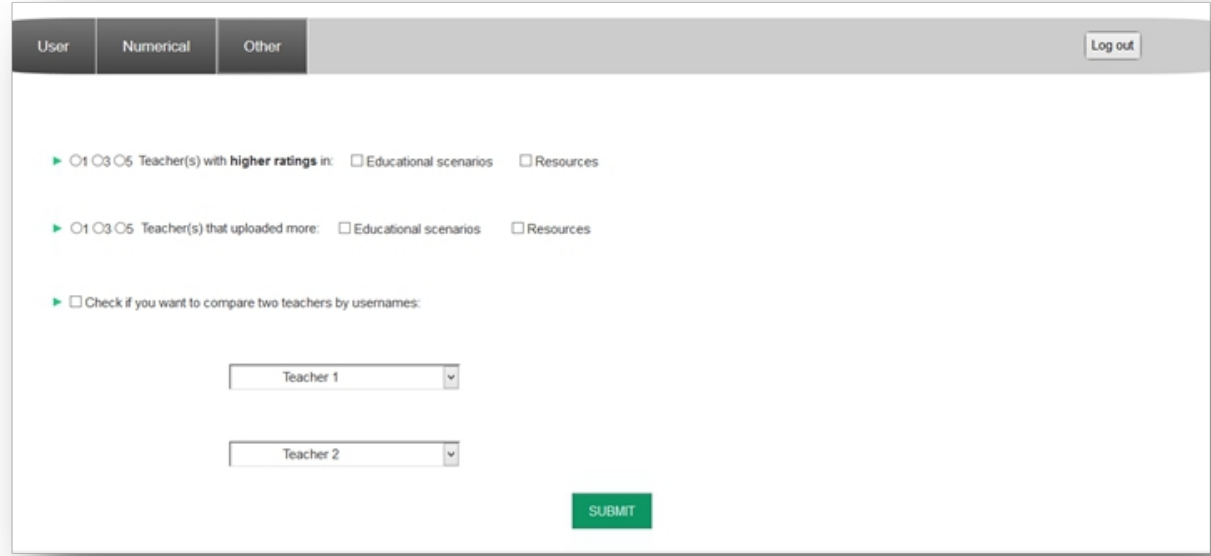

Figure 4. Results forms (3)

\section{Conclusions from a Case Study on System's Application}

In the current Section we present a showcase of using the developed tool to assist the investigation on the following specific research questions:

- Which are the most used social networking tools by teachers within an educational portal

- Which social networking tools are more used from the teachers with the most activation within an educational portal

- Which social networking tools gain most comments

- Correlation between teachers with the most educational resources upload and blog posts

For the purpose of research on the above research questions, we imported within the system data from an educational portal (with social networking tools included) used from teachers of primary or secondary education. This portal's main aim is to utilize Social Networking Tools with Peer Learning and Crowdsourcing to teach school communities to counter student bullying (Christodoulopoulou, 2016). The data imported in our tools from the SONETBULL Portal, includes 140 users in a period of one year with $50 \%$ of the users active in the portal. 


\begin{tabular}{|l|l|}
\hline Total users & 140 \\
\hline Total active users & 70 \\
\hline Blog posts created & 79 \\
\hline Educational scenarios & 102 \\
\hline Resources sharing & 123 \\
\hline Users created and managed groups & 14 \\
\hline
\end{tabular}

Table 1. Summary of data collected

\begin{tabular}{|l|l|}
\hline USER & Most used fucntionality \\
\hline A & Educational scenarios \\
\hline B & Resources sharing \\
\hline C & Resources sharing \\
\hline D & Resources sharing \\
\hline E & Resources sharing \\
\hline
\end{tabular}

Table 2. Most active users

The quantitative findings, based on the data collected using the developed tool are as follows:

- Active users have created 79 blogs (almost one per active user), uploaded and shared 102 educational scenarios and 123 educational object.

- 14 active users have created and managed groups.

- In active users groups the average number of blogs are 1,15, shared educational scenarios: 1,56 and shared resources: 1,89 .

- The 5 most active users are mainly sharing resources and scenarios.

- Most comments have been given in educational resources shared.

- There is no connection found between users with high level of activation in resources sharing and users' blog posts.

Based on the above findings (for the given specific sample coming from the SONETBULL Portal users) the derived conclusion in relation with the set Research Questions are as follows:

- Which are the most used social networking tools by teachers within an educational portal

The most used social networking tools are information sharing. Teachers are using mostly tools for resources and educational scenarios sharing. This is applied also for highly active teachers and for less active ones.

- Which social networking tools gain most comments

In relation which tools are gaining the most attention and interaction between users, sharing of educational scenarios is gaining the most interest and therefore the most comments from other teachers (comparing for example with blog posts). 
- Connection between teachers with the most educational resources upload and blog posts

The most activated teachers are mainly uploading and sharing resources and educational scenarios. However it seems that this does not mean that in the same time they are highly activate in blog posts. Sharing of resources does not mean necessarily that the teacher is also activated and motivated to exploit blogs usage.

\section{Further Work}

\section{Further work on technological level}

The presented e-tool can have several upgrades to include additional functionalities and capabilities, such as:

1. New reports and statistical information

- More detailed extracted reports (e.g. users with most comments on posts accompanied with additional information on date, connection with lesson, connection with user profile)

- Correlation of blog posts, educational scenarios uploaded, groups memberships etc with user profiles (e.g. educational level, age)

- Comparing reports and statistics from different educational portals

2. Improvements on reports' extraction

- Creation of Pdf reports

- Extract reports on XML

- Comparing reports and statistics from different educational portals

- Additional features on import portals functionality (e.g. to be able to include more types of social tools, or additional information from each portal)

3. Improvement on the User Interface

- Presenting the results with graphics apart from tables

- Creation of a mobile version

In general, this application could be configured differently, adding many other features that would make it even easier to use, exert a plethora of results with the main goal of developing and upgrading the imported portals and thus modernizing education. In any case, it is a first attempt for a centralized information system that can simply "take" data from collaborative educational portals, allowing the researcher (educational researcher) concerned to easily extract quantitative data to assess their impact. 


\section{Further work on pedagogical research level}

The developed tool and its expansion as described previously can be a very useful result to be used as a basis to carry out pedagogical research in relation with the use of social networking tools from teachers. By including more educational portals and additional functionalities, the researcher could work (in additional to qualitative research through questionnaires and interviews) on several research questions as follows:

1. What kind of social networking tools are useful for teachers' professional development?

Specific questions raised:

- What are the professional skills of a teacher which can be strengthened through social networking applications?

- Which social networking tools are the most appropriate to achieve professional development?

2. Which are the obstacles to effectively use such tools and which are the educational needs to deal with them?

- What educational activities can be efficiently supported by the social networking applications (with the effect of assisting the professional development of teachers)?

- What are the existing fears and insecurities of teachers in relation to use social networking tools?

- Which are the educational needs to address these?

3. Which are the proper indicators to effectively assess a relevant educational program?

$\circ$ What metrics can be used (through the use of social networking applications) for the evaluation of the above?

\section{Conclusion}

The application of new technologies in classroom has made the need for constant professional development even more important for teachers. They should be able to keep up with the technological development in the classroom and beyond. Integrating ICT into teaching is a complex process and one may encounter a number of difficulties. Teacher professional development is a development that they seek on their own so that they can meet the needs of their students or address issues derived from ICTs application in classroom leading to recognition as "reform-minded" educator.

The advent Social Web, has changed relationship to information and own personal and professional development opportunities outside of formal education. However, case studies and practical conclusions derived from them suggest that teachers are facing problems/ drawbacks in their effort to utilize social networking tools for their professional development (existing 
preconceptions, need for facilitation/support, needed structural changes in class / lessons organization etc).

Aim of the presented work was to additionaly contribute on the assessment of impact of Social Web applications for teachers' professional development proposing an ICT tool to be used for the collection of useful quantitative indicators which can provide a mean / basis for further evaluation supporting this impact assessment (e.g. by using qualitative research with questionnaires and interviews with teachers) in order to correlate their actual views with findings from quantitative results from the tool.

\section{References:}

1. Al-Jarf, R. (2013). ESL Teachers' Professional Development on Facebook. $3^{\text {rd }}$ International Conference on Foreign Language Teaching and Applied Linguistics (FLTAL). Sarajevo, Bosnia.

2. Anastasiou, A., Giavrimis, P., Papastamatis, A., Valkanos, E. (2011). Information and Communication Technologies (ICTs) and In-Service teachers' training. www.ccsenet.org/res Review of European Studies Vol. 3, No. 1; June 2011.

3. Anzai, Y. (2010). Factors that Affect Effective Integration of Social WebTechnologies in Language Education: Focusing on Podcasting and Wikis. Educational Studies. International Christian University.

4. Babatunde, E. (2017). The Influence of Social Media and Environmental Factors on Academic Performance of Student Nurses in South-West Nigeria, European Scientific Journal, Vol 13, No 10.

5. Barrett, T., McCulloch, J., McIntosh, E. (2011). Tweeting for teachers: how can social media support teacher professional development?, Pearson Center for Policy and Learning.

6. Beach, R. (2012). Can online learning communities foster professional development?. Language Arts, Volume 89 Number 4, March 2012.

7. Bhagwan, J., Sharma, A. (2015). Information and Communication Technology (ICT) in today's classroom. Journal of Business Management and Information Systems. Vol. 2, No. 1, Jan-June 2015.

8. Bruguera, C., Cuitert, M., Romeu, T. (2019). Social media and professional development: a systematic review. Research in Learning Technology, 27. https://doi.org/10.25304/rlt.v27.2286

9. Brunvand, S., Duran, M., Ellsworth, J., Sendag, S. (2012). Impact of Research-Based Professional Development: Investigation of Inservice Teacher Learning and Practice in Wiki Integration, JRTE | Vol. 44, No. 4, pp. 313-334 | C2012 ISTE | iste.org/jrte

10. Bultmann, M., Chatti, M., Dyckhoff, A., Shroeder, U., Zielke, D. (2012). Design and Implementation of a Learning Analytics Toolkit 
for Teachers, Journal of Educational Technology and Society, Vol. 15, Number 3.

11. Cachia, R. (2008). Social Computing: Study on the Use and Impact of Online Social Networking. IPTS Exploratory Research on the SocioEconomic Impact of Social Computing. European Commission JRS, Institute for prospective technological studies.

12. Cachia, R., Ferarri, A., Punie, Y. (2009), Innovation and Creativity in Education and Training in the EU Member States: Fostering Creative Learning and Supporting Innovative Teaching Literature review on Innovation and Creativity in E\&T in the EU Member States (ICEAC), JRC, European Commission.

13. Carter, H., Darby, S., Ewbank, A., Foulger, T., Reicks, P. (2013), License to Drive, License to Learn. Promoting Policy for Safe and Innovative Social Networking Use Schools, LEARNing landscapes, Vol6, No 2.

14. Christodoulopoulou, C., (2016), Presentation of the educational platform SONET-BULL, International Conference Anti-Bullying practices, Athens.

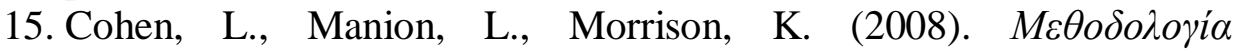

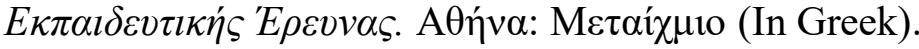

16. Couros, G., Hilt, L. (2011), Social Media as A professional Tool, National Association of Elementary School Principals (NAESP).

17. Coutinho, C.P., Lisboa, E.S. (2013), Social networks as spaces for informal teacher professional development: challenges and opportunities. Int. J. Web Based Communities, Vol. 9, No. 2.

18. Demkanin, P., Kibble, B., Lanoven, J., Guitart, Mas, J., Turlo, J. (eds). (2008), Effective Use of ICT in Science Education. EC, SOCRATES Commenius.

19. Dikova, L., Tepavicharova, M. (2019), Social media - on the edge between personal and professional development, Economics. Ecology. Socium, Vol 3 No 3.

20. Dunn, L.A. (2013). Teaching in Higher Education: Can Social Media Enhance the Learning Experience? University of Glasgow, School of Education.

21. edSurge co., (2014). How teachers are learning: Professional Development Remix. edSurge.com reports, June 2014.

22. Green, M., Powers, K. (2016), Principals Perspectives on Social Media in Schools, The Journal on Social Media in Society, 5 (2).

23. Groff, J., Haas, J., Klopfer, E., Osterwell, S. (2009), The Instructional Power of Digital Games, Social Networking, Simulations and Hoe Teachers Can Leverage Them, The Educational Arcade, Massachusetts Institute of Technology. 
24. Hargadon, S. (2010), Educational Networking: The important role Social Web will play in education. In: Education for a digital world, (editors: Sandy Hirtz and Kevin Kelly), Openschool.bc.ca

25. Hatter, D. (2012), Social Media \& Professional Development: A focus on Linkedin, Definity Partners.

26. Huang, H. (2017), The promise and Dilemma of the Mediated ParentTeacher Relationship in the Age of Social Networking Sites, Frontiers of Education in China, 2017, 12 (4): 468-489 DOI 10. 1007/s11516017-0034-1.

27. Instone, L. (2005). Conversations beyond the classroom: Blogging in a professional development course. Available from: https://pdfs.semanticscholar.org/da79/abdfa5fe57b355b891345b108e f30628cf20.pdf

28. Jones, A. (2004), A review of the research literature on barriers to the uptake of ICT by teachers, British Educational Communications and Technology Agency (Becta).

29. Karalis, T., Koskeris, A. (2016). Non - Formal Education Activities For The Enhancement Of Knowledge And Skills: Investigation Of Non-Explicit Motives For Participation, European Scientific Journal, Vol 12, No 19.

30. Kent County Council e-Safety Strategy Group. (2011), Using Social Media and Technology in Educational Settings. Considerations, guidance and risk assessment templates for schools and educational settings considering the use of Social Media. Kent County Council.

31. Kim, M., Lee, E. (2012), A Multidimensional Analysis Tool for Visualizing Online Interactions, Journal of Educational Technology and Society, Vol. 15, Number 3.

32. Kouzov, O., Pavlova, D. (2016), Unchain the education through mobility. UNESCO International Workshop: QED'16: Technology Advanced Quality Learning for ALL, June 13-15, 2016, Za Bukvite, O’Pismeneh Sofia. ISBN 978-619-185-163-8.

33. Luehmann, A., Tinelli, L. (2008). Teacher Professional Identity Development with Social Networking technologies: learning reform through blogging. Educational Media International, Vol. 45, No.4, December 2008, 323-333.

34. Luehmann, A. (2008). Using Blogging in Support of Teacher Professional Identity Development: A Case Study. THE JOURNAL OF THE LEARNING SCIENCES, 17: 287-337, Copyright @ Taylor \& Francis Group, LLC.

35. Madeira, S.A., Slota, J. (2009), Designing on-line communities to enhance teacher professional development, CSCL'09 Proceedings of 
the $9^{\text {th }}$ international conference on Computer Supported collaborative learning, Volume 2, Pages 79-81, Rhodes, Greece.

36. Mlotshwa, N. (2013). In what way do people respond to technology?, University of Derby, School of Computing and Mathematics.

37. Muqaddas, J., Sanobia, A., Nawaz, A. (2017). Impact of Social Media on Self-Esteem, European Scientific Journal, Vol 13, No 23.

38. Pereira Coutinho, Clara., Santana Lisbora, Eliana. (2013), Social Networks as spaces for informal teacher professional development: challenges and opportunities, Int. J. Web Based Communities, Vol. 9, No. 2, 2013.

39. Project tomorrow. (2011), The new 3 E's in Education: Enabled, Engaged, Empowered. How today's students are leveraging emerging technologies for learning, Speak UP 2010 National findings, K-12 students and parents, April 2011, Project tomorrow, 2011.

40. Shamoail, E. (2005). Teachers' Perception and Experiences in Adopting "Blackboard" Computer Program in a Vctorian Secondary School: A case study. Faculty of Human Development, School of Education, Victoria University, Victoria, Australia.

41. Smith, A. (2011). The role of SOCIAL WEBand Social Media Community in Education as a form of Teacher Professional Development. Department of Educational Studies, College of Education, University of Central Florida.

42. Stewart, S. (2009). Computer-Mediated Social Networking for Mentoring of Health Professionals. Computer-Mediated Social Networking, Springer.

43. Stone, T. (2010). Social Weband Social Learning Best Practices. 100+ Tips on the Use of Blogs, Wikis, and Forums in Organizations, Element K Corporation.

44. Tuviera-Lecaroz, S. (2002), Chapter 5: Teachers Using ICT for Networking and Professional Growth. Using ICT for Teaching Learning and Management. Unesco, 2002. 